\title{
Ingestion of mammalian meat and alpha-gal allergy: Clinical relevance in primary care
}

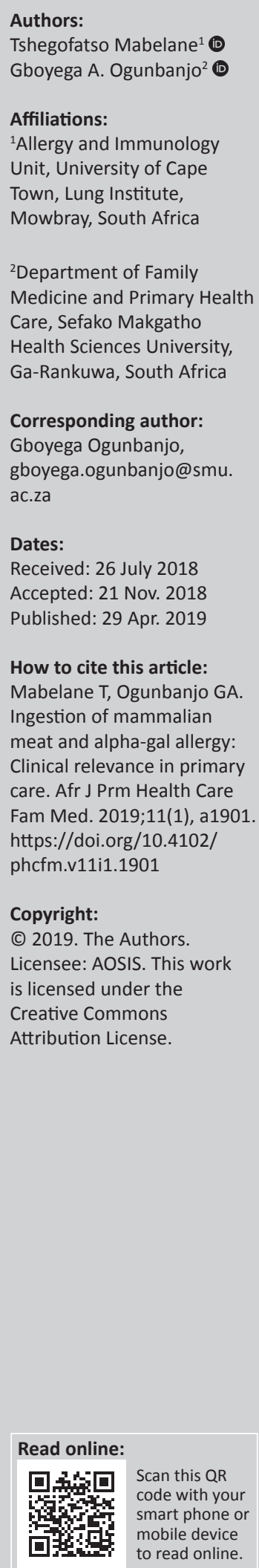

Background: An allergic reaction to mammalian meat has recently been reported in rural parts of South Africa and throughout other parts of the world. The cause of this allergic reaction is because of an oligosaccharide antigen known as galactose-alpha-1, 3-galactose (alpha-gal) found in mammalian meat. Hard ticks in various parts of the world have been identified as a cause of sensitisation to the alpha-gal antigen. However, mechanisms of sensitisation in Africa are poorly understood.

Aim: The aim of this article is to review current literature on the alpha-gal allergy and mammalian meat ingestion and the family physician's role in diagnosing and managing this condition.

Method: Indexes were searched using the keywords in the following electronic databases: Elsevier Science Direct, Google Scholar, Medline and PubMed.

Results: Clinical presentation of the alpha-gal allergy occurs typically as a delayed anaphylaxis occurring within 3-6 hours after the ingestion of mammalian meat. A subset of patients described in South Africa presented with a rapid onset of symptoms occurring within 45 minutes. Furthermore, some of these patients present with abdominal symptoms only, which may be mistaken as food poisoning. Diagnosis is based on a history of reaction to mammalian meats (especially to fatty portions or organs) and serum specific alpha-gal antibodies. The main management of the alpha-gal allergy is avoidance of red meat and in mild reactions treatment with oral $\mathrm{H} 1$ receptor antihistamines.

Conclusion: Sensitisation to the alpha-gal allergy results in adverse reactions to red meat, with tolerance to turkey, chicken and fish. A family physician can safely manage this condition.

Keywords: alpha-gal allergy; mammalian meat; management; primary care; specific IgE antibody; alpha-gal sensitisation.

\section{Introduction}

An immune mediated immunoglobulin $\mathrm{E}(\mathrm{IgE})$ antibody response to a mammalian oligosaccharide epitope, galactose-alpha-1, 3-galactose (alpha-gal), is associated with severe reactions after ingestion of mammalian meat (beef, pork, lamb, venison, goat and bison). Patients with allergic reactions to red meat have been reported worldwide.

\section{Methods}

The phrase 'alpha-gal allergy' along with 'mammalian meat adverse reactions' was initially used by the reviewers to search for articles. An article was included if it reported on a mammalian meat allergy with the clear distinction of other types of meat adverse reactions. Delayed reactions to mammalian meat were first described in 2009. Articles reporting on the alpha-gal antigen published between 1988 and 2017 in English were included in the search. Indexes in the following electronic databases were searched: Elsevier Science Direct, Google Scholar, Medline and PubMed.

\section{Review findings (results)}

\section{Sensitisations to alpha-gal antigen}

Studies in Sweden and France have reported clear evidence that the causative ticks for alpha-gal sensitisation is Ixodes ricinus, while in Australia it is Ixodes holocyclus which is implicated for the allergy. ${ }^{1,2,3,4}$ In the United States, the predominant, if not exclusive, cause is the Amblyomma americanum (see Figure 1). ${ }^{5}$ There may be other associated causative factors for alpha-gal sensitisation. Oligosaccharides are well recognised as a target for antibody response to helminths, and it is known that helminths and ecto-parasites can give rise to IgE responses. ${ }^{6,7}$ However, there are no consistent IgE antibodies to alpha-gal in the serum of patients with documented 


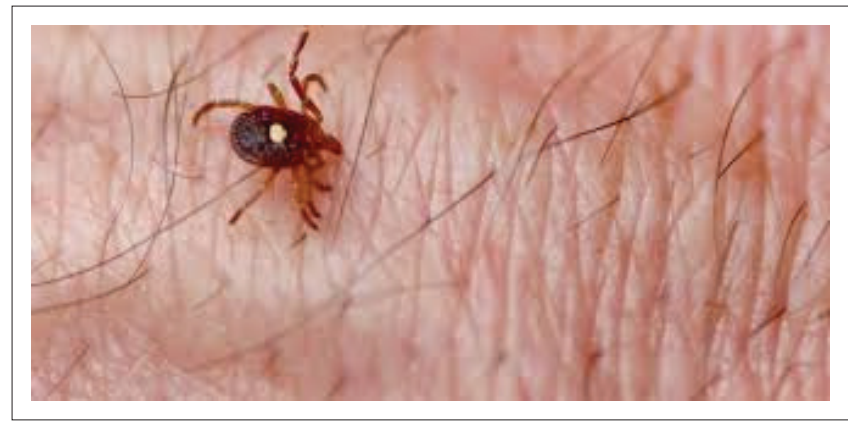

Source: Photograph by Lyle Buss.

FIGURE 1: Lone star tick (Amblyomma americanum). ${ }^{15}$

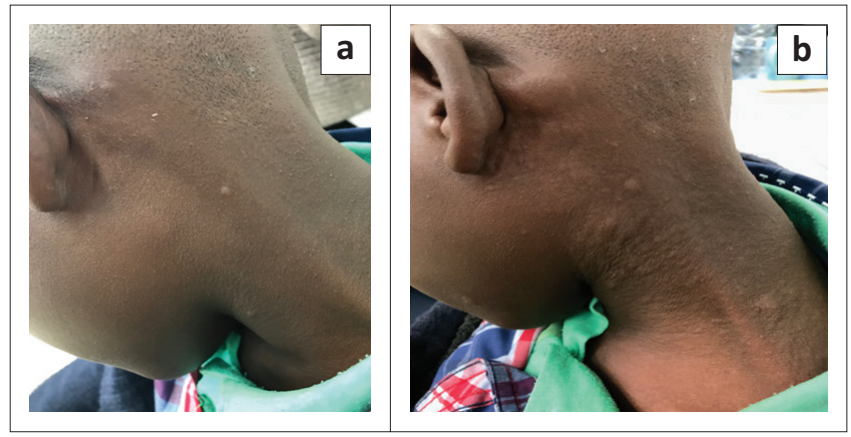

FIGURE 2: Progression of urticarial lesions during a reaction.

helminth infections. ${ }^{8}$ The detection of anti-gal binding sites in some strains of Escherichia coli, Klebsiella and Salmonella suggests that this antigen could be present in the bacterial polysaccharides on the outer membranes of the bacterial flora in human intestines. ${ }^{9,10}$ Primary sensitisation to catserum albumin may result in the low-level detection of alpha-gal antibodies, not associated with a meat allergy. ${ }^{11}$ Alpha-gal sensitisation has been described in Harare, Zimbabwe, $^{12,13}$ and Kenya ${ }^{12,14}$ and its association with the mammalian meat allergy in South Africa. ${ }^{15}$ However, no causative factors have been described.

\section{Alpha-gal in mammalian products}

Alpha-gal is found in all mammalian cells but not in human and Old-World monkey tissues. Mammalian meat and milk (cow and goat) contain alpha-gal. ${ }^{16}$ Mammalian animal byproducts may contain the alpha-gal epitope. However, animal by-products derived from turkey, chicken and fish do not contain the alpha-gal epitope. ${ }^{17}$

\section{Clinical presentations}

The alpha-gal allergy affects patients of all ages. Skin symptoms are commonly reported symptoms but may progress to anaphylaxis (see Figure 2). ${ }^{18}$ Research in the United States has shown that adult patients present with more severe reactions than children do. The onset of reactions is typically delayed and may result from eating meat 3-5 hours earlier. ${ }^{16}$ On the contrary, in South Africa, research conducted in the rural Eastern Cape showed a rapid onset of symptoms presenting with a high prevalence of gastrointestinal manifestation (abdominal pain, vomiting and diarrhoea). In some patients, sustained and severe abdominal pain was the only symptom without associated skin manifestations. In this cohort, severe symptoms were found to be more common in children than in adults. ${ }^{19}$

Reactions do not occur with every ingestion of red meat in comparison with a typical IgE-mediated food allergy where there is reproducibility of a reaction with every exposure to the trigger food. Patients mostly report reactions after eating large, fatty portions of red meat or organs, for example, kidney or liver. ${ }^{16}$ The rate of lipid absorption may play a role in the delayed reactions. Part of the delay may also be a result of conversion and processing of fats to chylomicrons and then further to low density lipoprotein particles of various sizes. ${ }^{20}$

\section{Diagnosis of alpha-gal allergy}

The diagnosis of the alpha-gal allergy is based on a good medical history, a relevant blood test and oral food challenge (only if indicated).

\section{Medical history}

A detailed food allergy history focuses on symptoms, timing of symptoms in relation to ingestion, list foods ingested around the time of the reaction, the consistency of reactions upon exposure, how the food was prepared, whether additional factors were occurring at the time (exercise, illness, use of non-steroidal anti-inflammatory drugs), whether symptoms also occur without relationship to ingestion, treatments given and the time-course of the symptoms. ${ }^{21}$

A positive history of adverse reaction to mammalian meat or other mammalian products is suggestive of the alpha-gal allergy. Patients over the age of 5 years with an apparent new onset milk allergy should be investigated for the alpha-gal allergy. ${ }^{21}$

\section{Blood test}

A blood sample of at least $2 \mathrm{~mL}$ is collected in a plain tube using standard procedures and can be stored at $2{ }^{\circ} \mathrm{C}-8^{\circ} \mathrm{C}$ for up to 1 week and sent to a laboratory for testing. The test is a fluoro enzyme immunoassay, and this method detects antibodies against an allergen. A patient's serum is coupled with the commercial alpha-gal antigen on a high binding capacity cellulose matrix. Any $\operatorname{IgE}$ that is specific for the antigen binds to the matrix. Anti-IgE is added to form a complex and make the antigen visible. ${ }^{22}$ Performing immunoassay testing for specific IgE to pork, beef and cat serum albumin is recommended to exclude other mammalian meat allergy conditions. ${ }^{16}$ There is a low titre of beef, pork or lamb sensitisation but high-specific IgE antibodies to alphagal. Sensitivity, specificity, negative predictive values and positive predictive values for alpha-gal IgE levels and alphagal: total IgE ratio, have been determined in the South African population. ${ }^{19}$

Patients with the alpha-gal allergy may have a positive blood test to cat $\operatorname{IgA}$ because of cross sensitisation. ${ }^{23}$ 


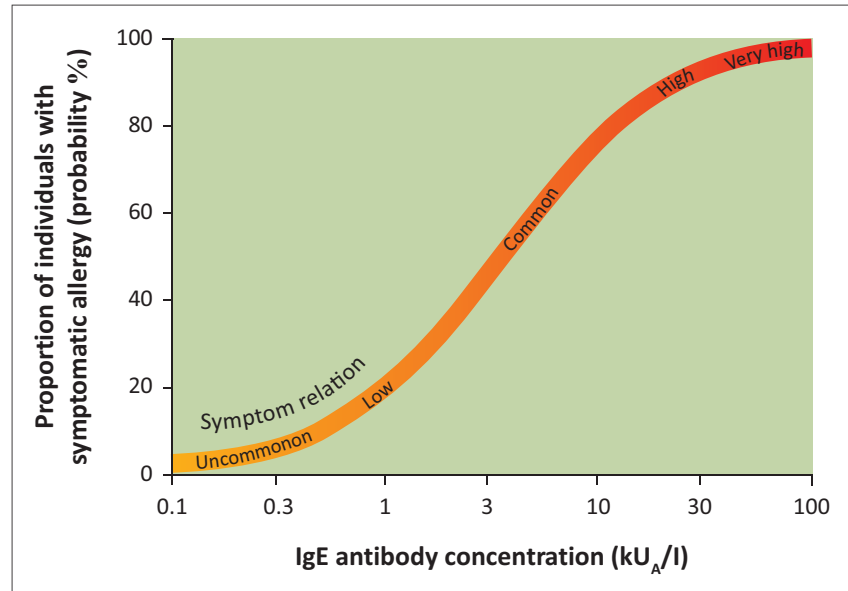

Source: Söderström L, Kober A, Ahlstedt S, et al. A further evaluation of the clinical use of Specific IgE antibody testing in allergic diseases. Allergy. 2003;58:921-928. https://doi. org/10.1034/j.1398-9995.2003.00227.x.

FIGURE 3: Specific IgE antibody levels and interpretation in symptomatic individuals. ${ }^{44}$

In clinical practice, specific IgE antibody levels of $0.35 \mathrm{kU} / \mathrm{L}$ are commonly considered as the cut-off point for sensitisation to an allergen. Low $\operatorname{IgE}$ antibody levels indicate a low probability of clinical disease, whereas high antibody levels to an allergen show a good correlation with clinical disease but not severity ${ }^{24}$ (see Figure 3).

Specific $\operatorname{IgE}$ antibodies are present in serum as a result of sensitisation and not necessarily allergy.

\section{Oral food challenge}

An open oral food challenge is performed in patients with alpha-gal antigen sensitisation but an unclear history of meat allergy. The principle of an oral food challenge is to give the suspected food in incremental doses at 15 minutes intervals, under close medical supervision. ${ }^{25}$ However, the alpha-gal allergy often presents with a delayed reaction and the oral food challenge is different from the traditional one. A full dose of $150 \mathrm{~g}$ of pork in an adult patient is given at once with close monitoring for at least $8 \mathrm{~h}$. Informed consent is obtained before the procedure, and an experienced allergy clinician with resuscitation skills performs this procedure. Beef challenges produce more severe reactions than pork. ${ }^{26}$

\section{Differential diagnosis}

\section{Pork-cat syndrome}

Pork-cat syndrome is an uncommon syndrome where patients develop an IgE antibody response specific for cat serum albumin that cross-reacts with porcine albumin. Patients classically present with a range of symptoms as in other food allergic reactions and the clinical symptoms are not predicted by the concentrations of specific IgE antibodies to cat serum albumin. The reaction is immediate and can be severe or even fatal upon consumption of pork. A subset of patients have presented with reactions to both pork and beef. . $72,28^{2}$ Positive specific IgE to pork and cat serum albumin and negative specific IgE antibodies to alpha-gal confirm the diagnosis of the pork-cat syndrome. The natural history of the pork-cat syndrome is not well established, but it appears that the specific IgE to cat serum albumin may slowly decrease over time. ${ }^{30}$

\section{Beef milk syndrome}

Between $10 \%$ and $20 \%$ of children who are allergic to cows' milk are also allergic to beef. Conversely, 93\% of children allergic to beef are also allergic to milk. The molecular basis for this syndrome is allergy to bovine serum albumin. ${ }^{31}$ Industrial treatment, more than home cooking, may modify the allergic reactivity of this meat in beef-sensitive children, making industrially freeze-dried or homogenized beef safe alternatives to butcher's meat cooked at home. ${ }^{32}$ Total avoidance of beef by children allergic to milk is not advised and needs an allergist's evaluation.

\section{Management}

\section{Non-medical management}

Education: The unpredictability of anaphylaxis may cause anxiety in patients and their families. A written action plan for the treatment of allergic reactions is useful in early identification of symptoms and appropriate management by patients and family members. Patients are instructed to wear bracelets that warn about alpha-gal hypersensitivity, for example, being allergic to red meat. ${ }^{21}$

Dietary management: The avoidance of red meat is the main management of the alpha-gal allergy. ${ }^{21}$ Patients react to red meat but usually tolerate other mammalian products. Clinical reactivity to all mammalian products results in complete avoidance strategies. An experienced dietitian with knowledge in the alpha-gal allergy will be the ideal person to guide a newly diagnosed patient with a mammalian meat allergy. Iron and vitamin $B_{12}$ are supplements that are recommended to prevent deficiencies in patients with a longstanding requirement for avoiding mammalian meat. ${ }^{33}$

\section{Medical}

\section{Immediate management}

Mild reactions such as urticaria or gastrointestinal symptoms are treated with oral $\mathrm{H}_{1}$ receptor antihistamines preferably in liquid form to enhance rapid absorption. However, there is evidence that other mediators such as platelet activating factors and kinins are associated with severe and potentially fatal reactions..$^{34,35}$ The progression of symptoms is unpredictable, and in these patients, adrenalin must be considered if symptoms do not resolve.

The first line management for severe reactions is with undiluted adrenalin 1:1000 (1 $\mathrm{mg} / \mathrm{mL}) \quad 0.01 \mathrm{~mL} / \mathrm{kg}$ (max $0.3 \mathrm{~mL}$ ) in children and $0.5 \mathrm{mg}$ intramuscularly (IMI) in adults administered on the anterolateral thigh. The adrenalin intramuscular injection results in a faster and better response, and a subcutaneous injection is not recommended. Another dose of adrenalin is repeated after $5 \mathrm{~min}$ if the patient did not respond. The patient is placed in a recumbent position. A call for help is necessary in managing patients with severe reactions. Patients on $\beta$-blockers are resistant to adrenalin and should receive glucagon 01.mg/ $\mathrm{kg}$ (maximum $1 \mathrm{mg}$ ) every $20 \mathrm{~min}$. Supportive treatment includes oxygen, 
bronchodilator and antihistamine. Corticosteroids are administered as second-line management to prevent a biphasic reaction. In hypotensive patients, resuscitation fluids are administered. Prolonged anaphylaxis requires extended observation and treatment. . $^{36,37}$

\section{Long-term management}

Adrenalin and a kit that includes syringes, needles, alcohol swabs and cotton are prescribed to patients with lifethreatening reactions to mammalian meat. An epipen autoinjector is more convenient and can be prescribed as either Epipen Junior ${ }^{\circledR} 0.15 \mathrm{mg}$ or Epipen Senior ${ }^{\circledR} 0.3 \mathrm{mg}$ or according to the manufacturer's specifications. Two sets of adrenalin are safe, especially in cases of a refractory reaction. ${ }^{37}$

\section{Clinical implications of alpha-gal allergy}

IgG antibodies against alpha-gal are naturally present in humans and constitute about $1 \%$ of circulating immunoglobulins in response to immune stimulation by enteric bacteria. ${ }^{38}$ Patients with the alpha-gal allergy produce $\mathrm{IgE}$ antibodies resulting in an allergic response.

\section{Hypersensitivity reaction to antivenom}

Deglycosylation assays and $\operatorname{IgE}$ inhibition tests confirmed that IgE-mediated reactivity to antivenom are associated with alpha-gal. Alpha-gal is a potential target of IgE-mediated reactivity to equine antivenom and a possible cause of the high incidence of hypersensitivity reactions during the first application of equine antivenom..$^{39}$

\section{Reactions to a prosthetic heart valve for aortic valve replacement}

Mozzicato et al. reported three patients with suspected alphagal allergies, and of those, two developed immunologic reactions from porcine or bovine aortic valve replacement. ${ }^{40}$ Bio prosthesis was associated with the presence of alpha-gal in the valve tissue. The evidence of this description was strengthened by other groups and also proven in experimental animal work. ${ }^{41,42,43}$

\section{Prognosis}

Specific IgE antibodies to alpha-gal appear to decrease over time. Patients with the alpha-gal allergy can have a resolution of symptoms and tolerate red meat again. However, symptoms re-occur with additional exposure to ticks. Followup is advised in these patients because of the possibility of reoccurrence after remission.

\section{Conclusion}

The alpha-gal allergy should be considered in patients with idiopathic anaphylaxis or multiple potential causes for both acute and chronic urticaria, as well as angioedema. ${ }^{21}$ Patients with abdominal symptoms upon exposure to red meat may need to be assessed for the alpha-gal allergy. Further research is needed on the causative factors of the alpha-gal allergy in Africa and understanding the mechanisms of sensitisations for the implementation of preventative strategies. Diagnosis is based on a history of reaction to mammalian meats (especially to fatty portions or organs) and serum specific alpha-gal antibodies. The main management of the alpha-gal allergy is avoidance of red meat and in mild reactions treatment with oral $\mathrm{H}_{1}$ receptor antihistamines.

\section{Acknowledgements Competing interests}

The authors declare that they have no financial or personal relationships that may have inappropriately influenced them in writing this article.

\section{Authors' contributions}

T.M. conceptualised and drafted the manuscript. G.A.O. critically revised and edited the manuscript for intellectual content.

\section{Disclaimer}

The views expressed in this article are those of the authors and not official positions of the two institutions.

\section{References}

1. Mullins RJ, James $H$, Platt-Mills TA, Commins S. Relationship between red meat allergy and sensitization to gelatin and galactose $\alpha-1,3$-galactose. J Allergy Clin Immunol. 2012;129:1334-1342. https://doi.org/10.1016/j.jaci.2012.02.038

2. Hamsten C, Starkhammer M, Tran TA, et al. Identification of galactose-alpha-1.3galactose in the gastrointestinal tract of the tick ixodes rinicus: Possible relationship with red meat allergy. Allergy. 2013;68(4)549-552. https://doi. org/10.1111/all.12128

3. Van Nunen SA, O'Connor KS, Clarke LR, Boyle RX, Fernando SL. An association between tick bite reactions and red meat allergy in humans. Med J Aust. 2009;190:510-511.

4. Morisset M, Richard C, Astier C. Anaphylaxis to pork kidney is related to IgE antibodies specific for galactose-alpha-1, 3-galactose. Allergy. 2012;67:699-704. https://doi.org/10.1111/j.1398-9995.2012.02799.x

5. Commins SP, James HR, Kelly LA, et al. The relevance of tick bites to the production of IgE antibodies to the mammalian oligosaccharide galactose-alpha-1, 3-galactose. J Allergy Clin Immunol. 2011;127:1286-1293. https://doi.org/10. 1016/j.jaci.2011.02.019

6. Addo-Yobo EOD, Woodcock A, Allotey A, Baffoe-Bonnie B, Strachan D, Custovic A. Exercise-induced bronchospasm and atopy in Ghana: Two surveys ten years apart. PLoS Med. 2007;4(2):0355-0360. https://doi.org/10.1371/journal.pmed.0040070

7. Faveeuw C, Mallevaey T, Paschinger K. Schistosome N-glycans containing core alpha 3-fucose and core beta 2-xylose epitopes are strong inducers of Th2 responses in mice. Eur J Immunol. 2003;33:1271-1281. https://doi.org/10.1002/ eji.200323717

8. Okano M, Satoskar AR, Nishizaki K, Abe M. Induction of Th2 responses and IgE is largely due to carbohydrate functioning as adjuvant on Schistosoma mansoni egg antigens. J Immunol. 1999;163:6712-6717.

9. Platts-Mills TAE, Schuyler AJ, Tripathi A, Commins SP. Anaphylaxis to the carbohydrate side chain alpha-gal. Immunol Allergy Clin North Am. 2015;35: 247-260. https://doi.org/10.1016/j.iac.2015.01.009

10. Galili U, Mandrell RE, Hamadeh RM, Shohet SB, Griffiss JM. Interaction between human natural anti-alpha-galactosyl immunoglobulin $G$ and bacteria of the human flora. Infect Immun. 1988;56(7):1730-1737.

11. Gonzalez-Quintela A, Dam Laursen AS, Vidal C, Skaaby T, Gude F, Linneberg A. IgE antibodies to alpha-gal in the general adult population: Relationship with tick bites, atopy, and cat ownership. Clin Exp Allergy. 2014;44(8):1061-1068. https:// doi.org/10.1111/cea.12326

12. Commins SP, Kelly LA, Ronmark E, et al. Galactose-alpha-1, 3-galactose-specific IgE is associated with anaphylaxis but not asthma. Am J Respir Crit Care Med. 2012;185:723-730. https://doi.org/10.1164/rccm.201111-20170C

13. Arkenstal K, Sibanda E, Thors $C$, et al. Impaired allergy diagnostic among parasiteinfected patients caused by IgE antibodies to the carbohydrate epitope galactosealpha-1, 3-galactose. J Allergy Clin Immunol. 2011;127:1025-1028.

14. Perzanowski MS, Nganga LW, Carter MC, et al. Atopy, asthma and antibodies to Ascaris among rural and urban children in Kenya. J Paediatr. 2002;140:528-528. https://doi.org/10.1067/mpd.2002.122937 
15. Gray CL, Van Zyl A, Strauss L. "Midnight anaphylaxis" to red meat inpatients with alpha-gal sensitisation: A recent discovery in the food allergy world and a case report from South Africa. Curr Allergy Clin Immunol. 2016;29(2):104

16. Commins SP, Platt-Mills TAE. Delayed anaphylaxis to red meat in patients with IgE specific for galactose alpha-1, 3-galactose (alpha-gal). Curr Allergy Asthma Rep. 2013;13(1):72-77. https://doi.org/10.1007/s11882-012-0315-y

17. Alpha gal basics. Alpha-gal allergy awareness website [homepage on the Internet]. 2014 [cited 27 May 2015. Available from: http://alpha-gal.org

18. Commins SP, Jeratha MR, Cox K, Erickson LD, Platts-Mills T. Delayed anaphylaxis to alpha-gal, an oligosaccharide in mammalian meat. Allergol Int. 2016;65(1):16-20. https://doi.org/10.1016/j.alit.2015.10.001

19. Mabelane T, Baresa W, Botha M, Facey-Thomas H, Levin M. Predictive values of alpha-gal IgE levels and alpha-gal IgE:total IgE ratio and oral food challenge proven meat allergy in a population with a high prevalence of reported red meat allergy. Pediatr Allergy Immunol. 2018;29(8):841-849. https://doi.org/10.1111/pai.12969

20. Wang $Y$, Ghoshal $S$, Ward $M$, et al. Chylomicrons promote intestinal absorption and systemic dissemination of dietary antigen (ovalbumin) in mice. PLoS One. 2009;4:e8442. https://doi.org/10.1371/journal.pone.0008442

21. Sampson HA, Aceves S, Allan Bock AS, et al. Food allergy: A practice parameter update-2014. J Allergy Clin Immunol. 2014;134:1016-1025. https://doi.org/10. 1016/j.jaci.2014.05.013

22. Motala C, Hawarden D. Diagnostic testing in allergy. S Afr Med J. 2009;99:531.

23. Commins SP, Satinover SM, Hosen J, et al. Delayed anaphylaxis, angioedema, or urticaria after consumption of red meat in patients with IgE antibodies specific for galactose-alpha-1,3-galactose. J Allergy Clin Immunol. 2009;123(2):426-424. https://doi.org/10.1016/j.jaci.2008.10.052

24. Canonica GW, Ansotegui IJ, Pawankar R, et al. A WAO-ARIA-GA2LEN consensus document on molecular-based allergy diagnostics. World Allergy Organ J. 2013;6(17):1-17. https://doi.org/10.1186/1939-4551-6-17

25. Sampson HA, Gerth van Wijk R, Bindslev-Jensen $C$, et al. Standardizing doubleblind, placebo-controlled oral food challenges: American Academy of Allergy, Asthma \& Immunology-European Academy of Allergy and Clinical Immunology Asthma \& Immunology-European Academy of Allergy and Clinical Immunology PRACTALL consensus report. J Allergy Clin
https://doi.org/10.1016/j.jaci.2012.10.017

26. Commins SP, James HR, Stevens W, et al. Delayed clinical and ex vivo response to mammalian meat in patients with IgE to galactose-alpha-1,3-galactose. J Allergy Clin Immunol. 2014;134(1):108-115. https://doi.org/10.1016/j.jaci.2014.01.024

27. Drouet $M$, Sabbah $A$. The pork/cat syndrome or crossed reactivity between cat epithelia and pork meat. Monogr Allergy. 1996;32:164-173.

28. Hilger C, Kohnen M, Grigioni F, Lehners C, Hentges F. Allergic cross-reactions between cat and pig serum albumin. Study at the protein and DNA levels. Allergy. 1997;52:179-187. https://doi.org/10.1111/j.1398-9995.1997.tb00972.x

29. Drouet M, Sabbah A, Le Sellin J, Bonneau JC, Gay G, Dubois-Gosnet C. Fatal anaphylaxis after eating wild boar meat in a patient with pork-cat syndrome. Allerg Immunol. 2001;33:163-165.
30. Savi E, Rossi A, Incorvaia C. Cat-pork syndrome: A case report with a three years follow-up. Eur Ann Allergy Clin Immunol. 2006;38:366-368.

31. García BE, Lizas MT. Cross-reactivity syndromes in food allergy. J Investig Allergol Clin Immunol. 2011;21(3):162-170.

32. Fiocchi $A$, Restani $P$, Riva $E$, et al. Heat treatment modifies the allergenicity of beef and bovine serum albumin. Allergy. 1998;53:798-802. https://doi.org/10.1111/ j.1398-9995.1998.tb03977.x

33. TiARA (Tick-induced Allergies Research and Awareness). Royal North Shore Hospital, Sydney, Australia: Allergies Provoked by Ticks [homepage on the Internet]. [cited 2013 Mar 26]. Available from: http://www.tiara.org.au/

34. Vadas P, Perelman B, Liss G. Platelet-activating factor, histamine, and tryptase levels in human anaphylaxis. J Allergy Clin Immunol. 2013;131:144e149.

35. Sala-Cunill A, Björkqvist J, Senter R, Guilarte M. Plasma contact system activation drives anaphylaxis in severe mast cell mediated allergic reactions. J Allergy Clin Immunol. 2015;135:1031e1043.

36. Muraro A, Roberts G, Worm M, et al. Anaphylaxis: Guidelines from the European Academy of Allergy and Clinical Immunology. Allergy. 2014;69(8):1026-1045. https://doi.org/10.1111/all.12437

37. Lieberman P, Nicklas RA, Randolph $C$, et al. Anaphylaxis-a practice parameter update 2015. Ann Allergy Asthma Immunol. 2015;115:341-384. https://doi. org/10.1016/j.anai.2015.07.019

38. Galili U, EA R, Peleg A, Flechner I. A unique natural human IgG antibody with anti$\alpha$-galactosyl specificity. J Exp Med. 1984;160(5):1519. https://doi.org/10.1084/ jem.160.5.1519

39. Fischer J, Eberlein E, Hilger C, et al. Alpha-gal is a potential target of IgE-mediated reactivity to equine antivenom and a possible cause of the high incidence of hypersensitivity reactions during the first application of equine antivenom. Alphagal is a possible target of IgE-mediated reactivity to antivenom. Allergy. 2017 72(5):764-771. https://doi.org/10.1111/all.13073

40. Mozzicato SM, Tripathi A, Posthumus JB, Platts-Mills TA, Commins SP. Porcine or bovine valve replacement in 3 patients with IgE antibodies to the mammalian oligosaccharide galactose-alpha-1,3-galactose. J Allergy Clin Immunol Pract. 2014;2(5):637-638. https://doi.org/10.1016/j.jaip.2014.04.016

41. Lim HG, Yoon EJ, Kim YK. In vivo efficacy of alpha galactosidase as possible promise for prolonged durability of bioprosthetic heart valve using alpha 1,3-galactosyltransferase knockout mouse. Tissue Eng Part A. 2013;19:2339-2348. https://doi.org/10.1089/ ten.tea.2013.0062

42. Park CS, Park SS, Choi SY, Yoon SH, Kim WH, Kim YJ. Anti-alpha-gal immune response following porcine bioprosthesis implantation in children. J Heart Valve Dis. 2010;19:124-130.

43. McGregor CG, Carpentier A, Lila N, Logan JS, Byrne GW. Cardiac xenotransplantation technology provides materials for improved bioprosthetic heart valves. J Thorac Cardiovasc Surg. 2011;141:269-275. https://doi.org/10.1016/j.jtcvs.2010.08.064

44. Söderström L, Kober A, Ahlstedt S, et al. A further evaluation of the clinical use of Specific IgE antibody testing in allergic diseases. Allergy. 2003:58:921-928. https://doi.org/10.1034/j.1398-9995.2003.00227.x 